\title{
A mild-symptom COVID-19 patient showed consistently high pharyngeal viral loads in a period of ten days after hospitalization
}

\section{Dong Chen}

ABLife BioBigData Institute https://orcid.org/0000-0003-2018-1120

\section{Shuqing Han}

Wuhan Red Cross Hospital

\section{Yue Sun}

ABLife Inc., Wuhan

\author{
Yisong Shen \\ Wuhan Red Cross Hospital \\ Xiaofei Zhou \\ Wuhan Red Cross Hospital \\ Yuanyuan Liu \\ ABLife Inc., Wuhan \\ Junfen Zhou \\ The Central Hospital of Wuhan \\ Nian Xiong \\ Huazhong University of Science and Technology \\ Yi Zhang ( $\nabla$ yizhang@ablife.cc) \\ https://orcid.org/0000-0003-1035-6134
}

\section{Research article}

Keywords: COVID-19, SARS-CoV-2, high viral load, RT-PCR

Posted Date: July 14th, 2020

DOl: https://doi.org/10.21203/rs.3.rs-41317/v1

License: (c) (i) This work is licensed under a Creative Commons Attribution 4.0 International License.

Read Full License 


\section{Abstract}

Background: The pandemics of coronavirus disease 2019 (COVID-19) threatens both human lives and health care system. COVID-19 patients may differ in their capability in spreading the causative virus, the severe acute respiratory syndrome-corona virus 2 (SARS-CoV-2).

Methods: In this study, oropharyngeal swabs specimens from 43 patients admitted to our hospital during the COVID-19 peak time in Wuhan, China were obtained to survey temporal profiles of the viral loads in their upper respiratory tract. An internal and an absolute mRNA control were included in the real-time RTPCR analysis and RNA extraction step to remove the potential influence of experimental variations on the result interpretation.

Results: We found about one third of the hospitalized COVID-19 patients were never tested as SARS-CoV2 positive during the course of this study. One patient with mild symptoms displayed constant high levels of viral loads after hospitalization, which were orders of magnitude higher than all other positive patients.

Conclusions: We propose that if pharyngeal viral loads in a patient could indicate its ability in spreading the virus to others, then identification and strict separation of the high viral load patients should provide an effective mean in restricting viral spreading and protect health care workers from infection.

\section{Background}

The outbreak of coronavirus disease 2019 (COVID-19) is one of the worst global health emergencies in modern times [1]. The severe acute respiratory syndrome-corona virus 2 (SARS-CoV-2) is the causive pathogen of COVID-19. The viral infection can cause fever, fatigue, dry cough and other symptoms, and severe cases may lead to respiratory failure and death [2,3]. Up to the time of submission of this paper, there were 10.46 million confirmed COVID-19 cases around the world, resulting in 0.51 million deaths (WHO COVID-19 dashboard, https://covid19.who.int). The outbreak of COVID-19 has substantially affected the world's economic and social activities in an all-round way, and caused incalculable physical and mental injuries to human beings. Particularly, the outbreaks threaten the health care systems, causing severe shortages in hospitalization spaces and facilities including ventilators, which is a major contributor to the much higher mortality rate in Hubei province than in the other provinces of China [4], and also contributes to the high mortality rate in other countries $[4,5]$. Meanwhile, the severe shortage in personal protection equipment can lead to the infection and death of medical doctors and nurses [5-7]. This complex situation can mentally stress all health care workers from different angles, which, if not probably handled, can reduce the efficiency of the hospitals in effectively combating COVID-19 [8-13].

Rapid and accurate detection of SARS-CoV-2 becomes available to control the outbreak of COVID-19. SARS-CoV-2 is single strand RNA virus, belonging to beta-coronavirus genera. Among the available methods in detecting SARS-CoV-2, the most common and accurate method is real-time RT-PCR which detects the viral RNA in the infected samples [14-16]. Nasopharyngeal and oropharyngeal swabs are the 
most popular samples for SARS-CoV-2 viral detection $[14,15,17]$. Saliva is recently reported to contain stably detectable viral RNA [16].

Preventing the spreading of SARS-CoV-2 inside of hospitals is a key in protecting health care workers. Super-spreaders caused severe infection and death of the medical personnel during the SARS outbreak in 2003 and also the followed MERS [18-20]. During SARS-CoV-2 outbreaks, superspreading events were also reported in the news during the national outbreaks associated with the Wuhan exposure, and were considered during modeling studies [21, 22]. However, superspreading associated with SARS-CoV-2 has not be well considered thus far, probably due to its much higher transmission feature than the other SARS. Characters of the super-spreaders remain elusive. Interestingly, some recently published results indicate the presence of substantial differences in the SARS-CoV-2 viral loads of the upper respiratory tract among different patients $[16,17]$. We suspected that the viral loads in the upper respiratory tract of different patients reflect their capability in spreading SARS-CoV-2. In this report, we collected oropharyngeal swabs from 43 hospitalized patients and studied the temporal dynamics of their viral loads. We surveyed whether there was a correlation between the detectable viral loads and the severity of the symptoms. We identified a patient showing drastically higher viral loads than all other patients in a duration of eight days of study.

\section{Methods}

We did a cohort study from one hospital in Wuhan. We included patients with laboratory-confirmed COVID-19 as well as patients without confirmation. We obtained specimens of pharyngeal swabs. We recorded and analyzed the history, physical findings, and haematological, biochemical, radiological, and microbiological investigation results. This study was approved by the Wuhan Red Cross Hospital institutional review board and the need for informed consent was waived. Adult patients with COVID-19 can be diagnosed as severe if they meet any of the following criteria; 1 . The respiratory rate is more than 30 times/min; 2. Oxygen saturation is less than or equal to $93 \%$ in resting state; 3 . Oxygenation index less than or equal to $300 ; 4$. The progress of pulmonary imaging is more than $50 \%$ in $24-48$ hours.

Specimens were first restored in TRIZOL, preserved by dry ice, and then Transported to laboratory within two hours. Total RNA was extracted by the TRIZOL (Ambion).

A $30 \mu \mathrm{L}$ reaction contained $3 \mu \mathrm{L}$ of RNA, $6 \mu \mathrm{L}$ of $5 \times$ HS HiTaq One Step RT-PCR Buffer(Mg2 + Plus), $3.6 \mu \mathrm{L}$

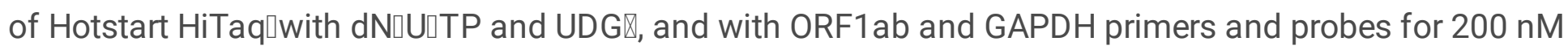
per reaction for duplex fluorescent PCR, while with EGFP primers and probe for $200 \mathrm{nM}$ per reaction for single gene reaction. Primer and probe sequences are shown in Table S1. All oligonucleotides were synthesised and provided by Sangon Biotech (Shanghai, China). Thermal cycling was performed at $25^{\circ} \mathrm{C}$ for $15 \mathrm{~min}$ to remove PCR amplification product contamination, and at $50^{\circ} \mathrm{C}$ for $20 \mathrm{~min}$ for reverse transcription, followed by $95^{\circ} \mathrm{C}$ for $10 \mathrm{~min}$ and then 40 cycles of $94^{\circ} \mathrm{C}$ for $15 \mathrm{~s}, 60^{\circ} \mathrm{C}$ for $30 \mathrm{~s}$. Participating laboratories used Applied Biosystems QuantStudio 6 instrument (Applied Biosystems, Sinapore). 
To amplify DNA fragment of EGFP, we used plasmid with EGFP (pLVshRNA-EGFP(2A) Puro, TranSheepBio, China) as the template through EGFP-T7-F and EGFP-T7-R primer amplified (shown in Table 1), used Phanta Max Super-Fidelity DNA Polymerase (P505-d1, vazyme, Nanjing, China), and gel extraction to purification the DNA(28704, QIAGEN). EGFP RNA is obtained by in vitro transcription using Transcript Aid T7 High Yield Transcription Kit (K0441, thermo). The integrity of RNA was further verified by $1.0 \%$ agarose gel electrophoresis. The quality and quantity of the purified RNA were redetermined by Qubit. 
Table 1

Clinical Characteristics of Patients in this study.

\begin{tabular}{|c|c|c|c|}
\hline & $\begin{array}{l}\text { Total } \\
\text { (43) }\end{array}$ & $\begin{array}{l}\text { Severe } \\
\text { (6) }\end{array}$ & Mild (37) \\
\hline Median age & 50 & 48.5 & 51 \\
\hline \multicolumn{4}{|l|}{ Sex } \\
\hline Male & 20 & 3 & 17 \\
\hline Female & 23 & 3 & 20 \\
\hline \multicolumn{4}{|l|}{ Complications } \\
\hline hypertension & 7 & 0 & 7 \\
\hline diabetes & 2 & 0 & 2 \\
\hline Cerebrovascular disease & 1 & 0 & 1 \\
\hline Hyperlipidemia & 2 & 0 & 2 \\
\hline Fatty liver & 1 & 1 & 0 \\
\hline History of hyperthyroidism & 1 & 1 & 0 \\
\hline Reflux esophagitis & 1 & 1 & 0 \\
\hline Coronary atherosclerotic heart disease & 3 & 0 & 3 \\
\hline Hypertensive heart failure & 1 & 0 & 1 \\
\hline Secondary hypothyroidism & 2 & 0 & 2 \\
\hline chronic bronchitis & 1 & 0 & 1 \\
\hline $\begin{array}{l}\text { Chronic obstructive pulmonary disease with acute } \\
\text { exacerbation }\end{array}$ & 1 & 0 & 1 \\
\hline \multicolumn{4}{|l|}{ Signs and symptoms } \\
\hline Fever & 31 & 6 & 25 \\
\hline Fatigue & 7 & 1 & 6 \\
\hline Dry cough & 30 & 4 & 26 \\
\hline asthma & 4 & 0 & 4 \\
\hline anorexia & 14 & 2 & 12 \\
\hline Muscle soreness & 7 & 2 & 5 \\
\hline dyspnea & 8 & 0 & 8 \\
\hline Expectoration & 7 & 2 & 5 \\
\hline
\end{tabular}




\begin{tabular}{|llll|}
\hline & $\begin{array}{l}\text { Total } \\
(\mathbf{4 3})\end{array}$ & $\begin{array}{l}\text { Severe } \\
(\mathbf{6})\end{array}$ & Mild (37) \\
\hline Sore throat & 4 & 0 & 4 \\
\hline Chills & 5 & 1 & 4 \\
\hline diarrhea & 3 & 0 & 3 \\
\hline nausea & 4 & 1 & 3 \\
\hline Palpitation & 1 & 0 & 1 \\
\hline Chest tightness & 13 & 1 & 12 \\
\hline Chest pain & 4 & 0 & 4 \\
\hline headache & 1 & 0 & 1 \\
\hline Vomit & 1 & 0 & 1 \\
\hline Chest and back discomfort & 1 & 1 & 0 \\
\hline Onset of symptom to (day) & & & \\
\hline Hospital admission (median) & 10 & 6 & 10 \\
\hline Heart rate, median (IQR), bpm & 82 & 90 & 82 \\
\hline Respiratory rate, median (IQR) & 18 & 18 & 18 \\
\hline Mean arterial pressure, median (IQR), $\mathrm{mm} \mathrm{Hg}$ & 93 & 90 & 93 \\
\hline
\end{tabular}

\section{Results}

\section{Study design and participants}

A total of 43 patients were included in this study. The age distribution of patients ranges from 24 to 87 , with about $80 \%$ patients age over 40 (Fig. 1A). None of the patients in this study required intensive care unit (ICU) nor a ventilator assistance, while six of them showed more severe symptoms than the others. All patients received CT imaging when they were admitted to hospital, and all the results showed groundglass opacification or mixed ground-glass opacification and consolidation. 31 (72.09\%), 13 (30.23\%), and $30(69.77 \%)$ patients had fever, dyspnea, and dry cough symptoms, respectively (Table 1). Because of the urgency and local policy, not all patients had a positive testing result of SARS-Cov-2 when they were admitted to hospital. At the time of or after admitting to hospital, 23 patients $(53.49 \%)$ were tested positive for SARS-CoV-2 at least once (Fig. 1B). Pharyngeal swabs from two patients were collected on $21 \mathrm{st}$, and those from all patients were collected on 23th, 25th, and 28th of February, 2020. The swabs were directly immersed in Trizol to preserve RNA during transportation and storage. We obtained specimens from 39 and 31 patients at 25th, and 28th, because 12 patients reached the standards of 
being healed and were discharged from the hospital during this study (Fig. 1B). The testing results did not interfere the treatment or the continuing testing for the SARS-Cov-2 appointed by CDC used as a criterion for the judgment of the healing state.

\section{About one third of the hospitalized COVID-19 patients were never tested as SARS-CoV-2 positive during the course of this study}

Real-time RT-PCR experiments were performed to detect the levels of viral RNA in each swab. To eliminate the possibility of the failure in sample collection and RNA preparation, which may influence the data interpretation, we added two controls. GAPDH was set as the internal control to monitor the total host mRNAs isolated from each swab and the effectiveness of the RT-PCR experiments. In order to directly monitor the effectiveness of the RNA preparation step, we added a fixed copy number of the in vitro transcribed EGFP RNA in Trizol prior to the RNA preparation step. According to the thresholds described in methods, 11 of 43 (25.58\%), 7 (17.95\%) and 9 of 31 (29.03\%) hospitalized patients were tested positive at 23th, 25th, and 28th sampling points, respectively (Fig. 1B). The lower positive rate at 25th could be due to the insufficient testing performed for the samples at this sampling point. Taken together, 3 patients (6.98\%) showed consistent positive testing results during the hospitalization. Fifteen patients $(34.88 \%)$ were transformed from positive to negative testing results, and not returned to positive during this study, among which 6 of them (40\%) reached the criteria of being healed and were discharged (Fig. 1C). On the other hand, 11 patients $(25.58 \%)$ showed alternating positive/negative testing results during this study, and only one of them $(9.09 \%)$ reached the criteria of being healed and was discharged. The remaining 14 patients (32.56\%) never showed positive results, and 5 (35.7\%) were healed and discharged (Fig. 1C).

In each set of our experiments, we included a series of the copy number dilution of the in vitro transcribed mRNA fragments from the viral ORF1ab gene, human GAPDH gene, as well as an external EGFP gene in some sets of experiments, in the reverse transcription reactions. Standard curves for calculating the correlation efficiency between $\mathrm{Ct}$ value and mRNA copies were therefore generated, and the mRNA copy number from each RT-qPCR positive reaction was calculated. We then selected all the samples tested positive for SARS-CoV-2 in this study, and plotted their copy numbers of viral mRNA, GAPDH mRNA, and EGFP mRNA in some benches of experiments, according to the sampling time points. Slightly higher viral loads were observed for specimens at the 23rd sampling time compared with those at 25th and 28th (Fig. 1D), consistent with the time-dependent reduction in viral loads. Meanwhile, the distribution of the mRNA copy numbers of GAPDH showed no such a time-dependent change (Fig. 1E).

\section{The pharyngeal viral loads differed significantly and a mild- symptom COVID-19 patient showed consistently high levels}


We noticed that the swab samples collected from the two patients at 21th February, 2020 were both positive, and one of them (Patient 14) showed $~ 5$ orders of magnitude higher viral load than the other (Patient 6) (Fig. 2A). Because Patient 14 was mild-symptomic, while Patient 6 was severe-symptomic, this observation indicated that the pharyngeal viral loads was not correlated with the severity of the symptoms.

To further explore this observation, we examined all benches of our real-time RT-qPCR analysis. We found that among seven benches of experiments containing more than 10 patient samples and a Patient 14 sample. Patient 14 was tested positive in six benches, representing the highest positive frequency among all samples. Strikingly, in each bench of the experiment including Patient 14 sample, the detected viral loads from Patient 14 was consistently higher than all the other samples (Fig. 2B). However, the copy numbers of GAPDH and EGPF mRNAs were normal (Fig. 2C-D). The viral loads from Patient 14 pharyngeal samples remained at high levels throughout this study, until the 10th day of the hospitalization of this patient.

Finally, we followed the prognosis outcome of participated patients. Up to time we submitted the manuscript, all of the patients were recovered and met the discharge criteria. No death was found among the patients. Patient 14 was healed and discharged 24 days after being hospitalized. All patients in this study were hospitalized in two separate areas of our hospital, 2 medical personnel worked at the inpatient area of patient 14 were infected, while there was no infected medical personnel at the other area. It was unclear whether the infection was related to Patient 14.

\section{Discussion}

Coronavirus SARS-Cov-2, the causative agent COVID-19, are commonly detected in the upper respiratory tract during the early stage of the infection $[17,23]$. It is recently emerging that the viral load in each patient could differ significantly [16], which may provide a plausible mechanism for super-spreaders. Identification of the super spreaders could play a key role in controlling the viral spreading in hospitals and protecting health care workers. Particularly, when the health care system is threatening, separation of the high viral load patients from the low viral load patients could also save health care resources.

In this study, we accurately monitored the dynamics of viral loads in the oral pharyngeal swabs of 43 patients, by applying standard curves and two quantitative internal controls. Our results showed that about $1 / 3$ of these patients were never shown positive during the course of these study, even multiple tests were performed for most of the samples in the three sampling times. There were only two previously negative patients were tested positive during this study, both demonstrating very low copy numbers. Most positive patients displayed alternative positive and negative, showing low viral loads as well.

The low viral loads in the oral pharyngeal swabs of most patients shown in this study may explain the presence of false negative results from real-time quantitative PCR detection that ever raised hot debates in China during the early time of the outbreaks. Similar as what has been found in this study, the detection rate through pharyngeal swab sampling detection of about $30 \%$ has also been reported in other 
studies [24]. Patients with positive chest CT findings but present with negative results of RT-qPCR for SARS-CoV-2 were quite common [25]. To overcome the detection limitation, all patients with positive chest CT evidence were diagnosed as potential COVID-19 patients and admitted to regular hospitals and shelter hospitals for treatments in Wuhan during the peak infection time in the middle February.

Only three patients showed constant positive results, and relatively high viral loads. Among these three constant positive patients, one showed severe symptoms and was admitted to the hospital at January 28th, and the other two were mild symptomatic and admitted at February 14th and 19th. Patient 14 carrying the persistent super-high viral loads in the upper respiratory tract was mild-symptomatic. Our results showed no correlation between severity of the symptoms and pharyngeal viral loads, which is consistent with the notion that the severity of symptoms is primarily due to the SARS-CoV-2 infection of the lower respiratory tract [26]. Interestingly, it is recently reported that the expression level of ACE2, the angiotensin I converting enzyme 2 and the cellular receptor for SARS-CoV-2, is not only high within pulmonary alveoli, the site of severe disease development; but also high within the sinonasal cavity, site of presumptive viral transmission [27].

We were not able to study the viral spreading capability of Patient 14 in this study. We noticed that the first COVID-19 patient reported in Washington, the United States carried high pharyngeal viral load as reflected by the low detected Ct. [28]. In the future, the correlation between the pharyngeal viral loads of a patient and its capability in spreading virus could be tracked back by the combination of the viral genome analysis and the original data on the pharyngeal viral loads of a potential super spreader. The correlation should also be carefully monitored in the future for the sake of the protection of the medical personnel.

Although it has not been documented, some asymptomic COVID-19 super spreaders had been reported in the news during the pandemic hit China. It could be possible that some asymptomic patient carry high pharyngeal viral loads. If that could be true, asymptomic COVID-19 patients who carry high pharyngeal viral loads should be quickly isolated, instead of putting in quarantine at home with family members.

\section{Conclusions}

Effective large-scale detection of the population is a favorable measure to identify the patients infected with COVID-19 [29, 30]. Nevertheless, results from our study showed that the majority of the COVID-19 patients carry low viral loads in the upper respiratory tract, but a small population of them carry high viral loads. Separation of these two different population of patients could be a key in controlling the viral spreading and outbreaks, protecting the population from attacking by the potential super spreaders, and also in saving medical care resources and protecting medical care workers from infection. Therefore, accurate report of the viral loads in the patient upper respiratory tract should be required in the future test, so that the doctors can make more precise decisions in setting up protection levels.

\section{Abbreviations}


CDC: centers for disease control and prevention; COVID-19: corona virus disease 2019; MERS: middle east respiratory syndrome; RT-PCR: reverse transcription-polymerase chain reaction; SARS-CoV-2: severe acute respiratory syndrome coronavirus 2 ;

\section{Declarations}

\section{Ethics approval and consent to participate}

This study was approved by the Wuhan Red Cross Hospital institutional review board and the need for informed consent was waived.

\section{Consent for publication}

All the patients in this study agreed for publication of this case report and any accompanying images. Written consent was waived.

\section{Availability of data and materials}

The data supporting the conclusions discussed in this article are included within the article.

\section{Competing interests}

The authors declare that they have no competing interests.

\section{Funding}

None.

\section{Authors' contributions}

DC, NX and YZ contributed to study design, data analysis, data interpretation, the literature search, and writing of the report. SH, YS, XZ, YL, and JZ contributed to patients' recruitment, data collection, and clinical management. YS and YZ contributed to the experiments, data collection, data analysis, and data interpretation. All authors reviewed and approved the final version of the report.

\section{Acknowledgments:}


We thank medical workers in Wuhan Red Cross Hospital and technicians in ABLife Inc., Wu for technical assistance and data collection.

\section{Trial registration}

Retrospectively registered

\section{References}

1. Perlman S. Another Decade, Another Coronavirus. N Engl J Med 2020.

2. Wang D, Hu B, Hu C, Zhu F, Liu X, Zhang J, Wang B, Xiang H, Cheng Z, Xiong Y, et al: Clinical Characteristics of 138 Hospitalized Patients With 2019 Novel Coronavirus-Infected Pneumonia in Wuhan, China. JAMA 2020.

3. Guan WJ, Ni ZY, Hu Y, Liang WH, Ou CQ, He JX, Liu L, Shan H, Lei CL, Hui DSC, et al: Clinical Characteristics of Coronavirus Disease 2019 in China. N Engl J Med 2020.

4. Ji Y, Ma Z, Peppelenbosch MP, Pan Q. Potential association between COVID-19 mortality and healthcare resource availability. The Lancet Global Health 2020, 8(4).

5. Ranney ML, Griffeth V, Jha AK. Critical Supply Shortages - The Need for Ventilators and Personal Protective Equipment during the Covid-19 Pandemic. N Engl J Med. 2020;382(18):e41.

6. Newman M. Covid-19: doctors' leaders warn that staff could quit and may die over lack of protective equipment. BMJ. 2020;368:m1257.

7. Wang J, Zhou M, Liu F. Reasons for healthcare workers becoming infected with novel coronavirus disease 2019 (COVID-19) in China. J Hosp Infect. 2020;105(1):100-1.

8. Chen Q, Liang M, Li Y, Guo J, Fei D, Wang L, He L, Sheng C, Cai Y, Li X, et al. Mental health care for medical staff in China during the COVID-19 outbreak. Lancet Psychiatry. 2020;7(4):e15-6.

9. Shanafelt T, Ripp J, Trockel M. Understanding and Addressing Sources of Anxiety Among Health Care Professionals During the COVID-19 Pandemic. JAMA 2020.

10. Ayanian JZ: Mental health needs of health care workers providing frontline COVID-19 care. In: JAMA Health Forum: 2020: American Medical Association; 2020: e200397-e200397.

11. Liu S, Yang L, Zhang C, Xiang Y-T, Liu Z, Hu S, Zhang B. Online mental health services in China during the COVID-19 outbreak. The Lancet Psychiatry. 2020;7(4):e17-8.

12. Duan L, Zhu G. Psychological interventions for people affected by the COVID-19 epidemic. Lancet Psychiatry. 2020;7(4):300-2.

13. Organization WH: Mental health and psychosocial considerations during the COVID-19 outbreak, 18 March 2020. In.: World Health Organization; 2020.

14. Jin YH, Cai L, Cheng ZS, Cheng H, Deng T, Fan YP, Fang C, Huang D, Huang LQ, Huang Q, et al. A rapid advice guideline for the diagnosis and treatment of 2019 novel coronavirus (2019-nCoV) infected pneumonia (standard version). Mil Med Res. 2020;7(1):4. 
15. Corman VM, Landt O, Kaiser M, Molenkamp R, Meijer A, Chu DK, Bleicker T, Brunink S, Schneider J, Schmidt ML, et al: Detection of 2019 novel coronavirus (2019-nCoV) by real-time RT-PCR. Euro Surveill 2020, 25(3).

16. To KK-W, Tsang OT-Y, Leung W-S, Tam AR, Wu T-C, Lung DC, Yip CC-Y, Cai J-P, Chan JM-C, Chik TS-H, et al: Temporal profiles of viral load in posterior oropharyngeal saliva samples and serum antibody responses during infection by SARS-CoV-2: an observational cohort study. The Lancet Infectious Diseases 2020.

17. Zou L, Ruan F, Huang M, Liang L, Huang H, Hong Z, Yu J, Kang M, Song Y, Xia J, et al. SARS-CoV-2 Viral Load in Upper Respiratory Specimens of Infected Patients. N Engl J Med. 2020;382(12):11779.

18. Shen Z, Ning F, Zhou W, He X, Lin C, Chin DP, Zhu Z, Schuchat A. Superspreading SARS events, Beijing, 2003. Emerg Infect Dis. 2004;10(2):256-60.

19. Wong G, Liu W, Liu Y, Zhou B, Bi Y, Gao GF. MERS, SARS, and Ebola: The Role of Super-Spreaders in Infectious Disease. Cell Host Microbe. 2015;18(4):398-401.

20. Lloyd-Smith JO, Schreiber SJ, Kopp PE, Getz WM. Superspreading and the effect of individual variation on disease emergence. Nature. 2005;438(7066):355-9.

21. Kucharski AJ, Russell TW, Diamond C, Liu Y, Edmunds J, Funk S, Eggo RM. Centre for Mathematical Modelling of Infectious Diseases C-wg: Early dynamics of transmission and control of COVID-19: a mathematical modelling study. Lancet Infect Dis. 2020;20(5):553-8.

22. Liu Y, Eggo RM, Kucharski AJ. Secondary attack rate and superspreading events for SARS-CoV-2. Lancet. 2020;395(10227):e47.

23. Zhou J, Chen L, Zhang D, Chen H, Sheng Q, Deng H, Zhang Y, Ni S, Luo S, Ren B: Optimal upper respiratory tract sampling time for novel coronavirus pneumonia suspects. medRxiv 2020.

24. Wang W, Xu Y, Gao R, Lu R, Han K, Wu G, Tan W: Detection of SARS-CoV-2 in Different Types of Clinical Specimens. JAMA 2020.

25. Xie X, Zhong Z, Zhao W, Zheng C, Wang F, Liu J. Chest CT for Typical 2019-nCoV Pneumonia: Relationship to Negative RT-PCR Testing. Radiology 2020:200343.

26. Paules $\mathrm{Cl}$, Marston HD, Fauci AS. Coronavirus infections-more than just the common cold. Jama. 2020;323(8):707-8.

27. ME OB, Thurman A, Pezzulo A, Leidinger M, Klesney-Tait J, Karp P, Tan P, Wohlford-Lenane C, McCray P, Meyerholz D: Heterogeneous expression of the SARS-Coronavirus-2 receptor ACE2 in the human respiratory tract. 2020.

28. Holshue ML, DeBolt C, Lindquist S, Lofy KH, Wiesman J, Bruce H, Spitters C, Ericson K, Wilkerson S, Tural A, et al: First Case of $\mathbf{2 0 1 9}$ Novel Coronavirus in the United States. N Engl J Med 2020.

29. Wang F-S, Zhang C. What to do next to control the 2019-nCoV epidemic? The Lancet. 2020;395(10222):391-3.

30. Beeching NJ, Fletcher TE, Beadsworth MBJ. Covid-19: testing times. BMJ. 2020;369:m1403. 
A

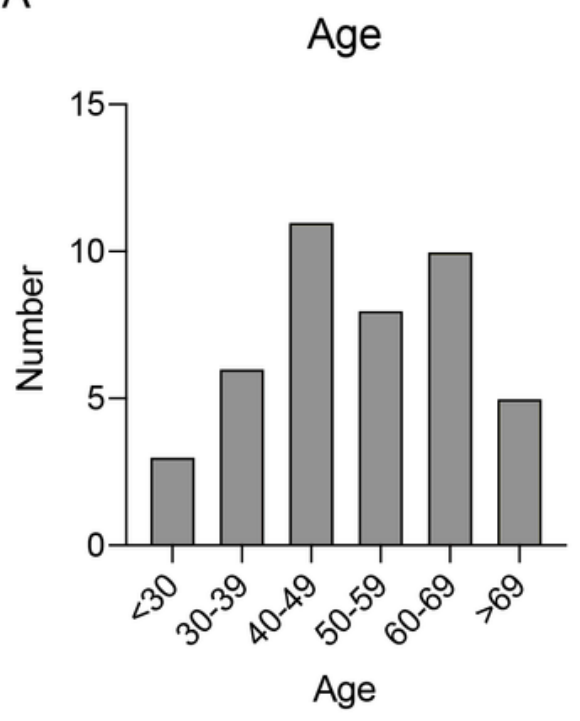

C

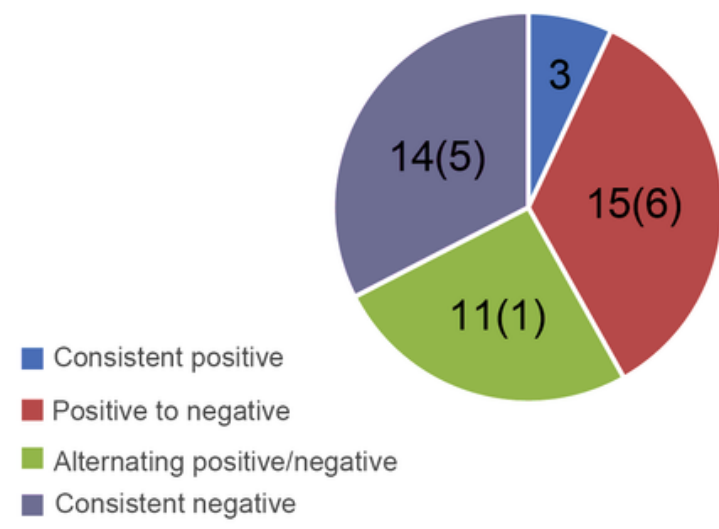

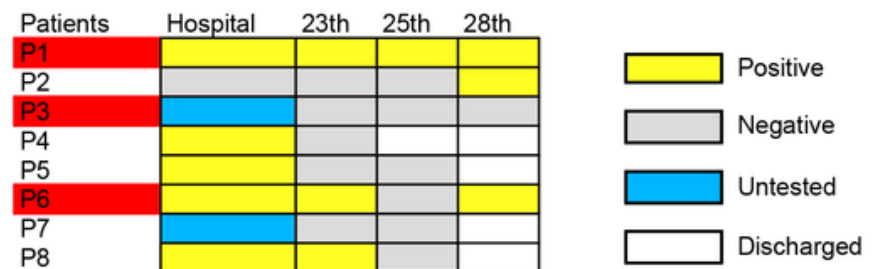

E

GAPDH load

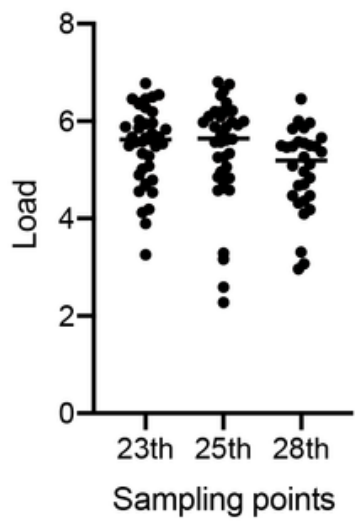

\section{Figure 1}

The detection results of all the specimens from 43 patients of COVID-19. (A) Bar plot showed the age distribution of the 43 participated patients. (B) Heat map showed the testing results of the 43 patients in hospital and the following sampling points. Patients with red background were severe cases. Yellow 
background represented positive results, grey for negative. Blue background represented untested patients when they were admitted to hospital. White background represented for discharged patients because of recuperation. (C) Pie chart showed the classification of testing results. Numbers in the brackets represented discharged patients. (D) Dot plot showed the viral load distribution from the three sampling points (mean $\pm S D$ ). (E) Dot plot showed the copy numbers (log10 per $15 \mathrm{um}$ ) of GAPDH during the experimental processes.

A

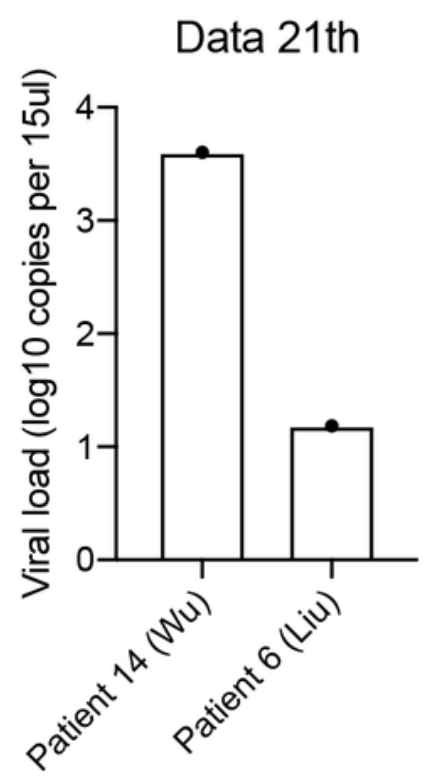

Patients

C

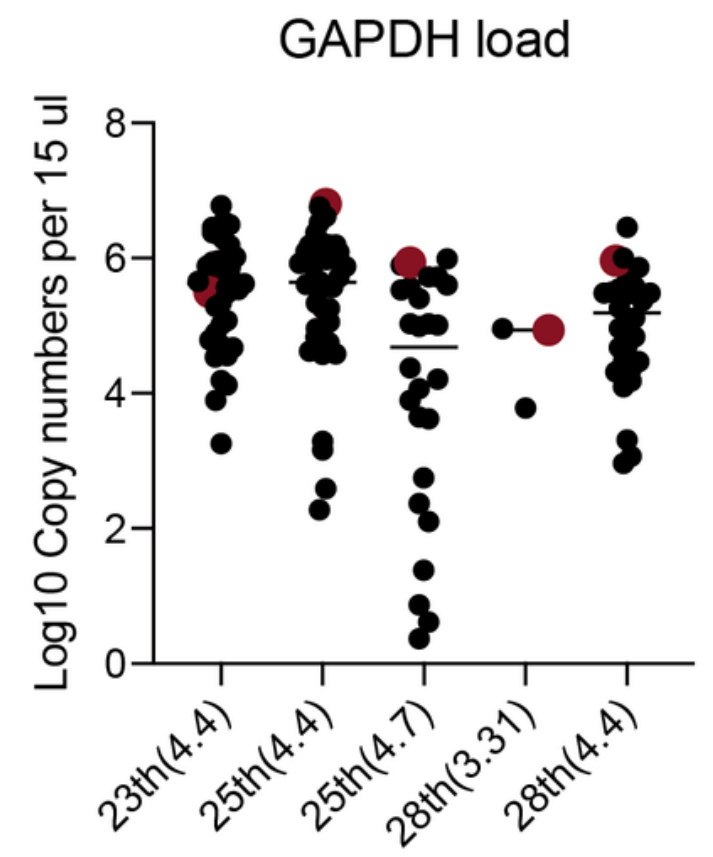

Sampling points
B

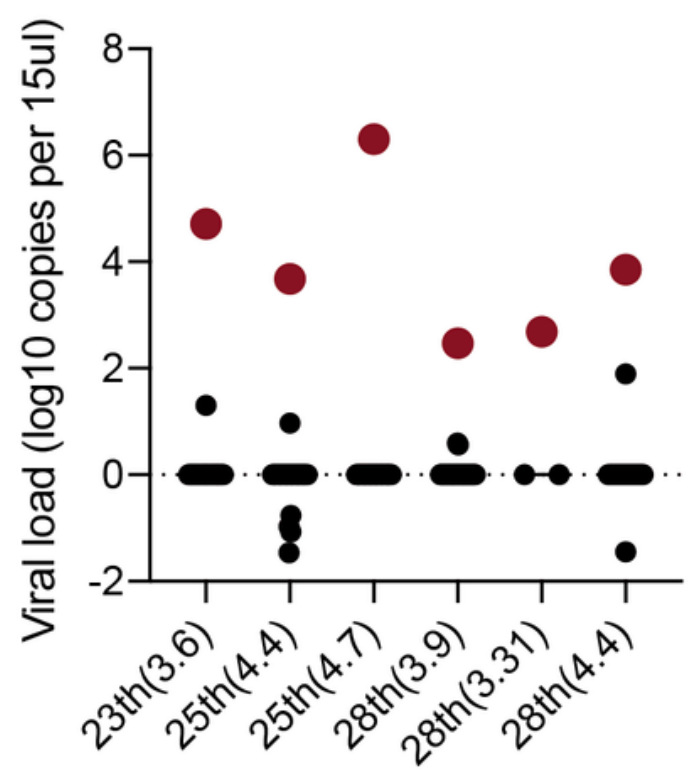

Batch

D

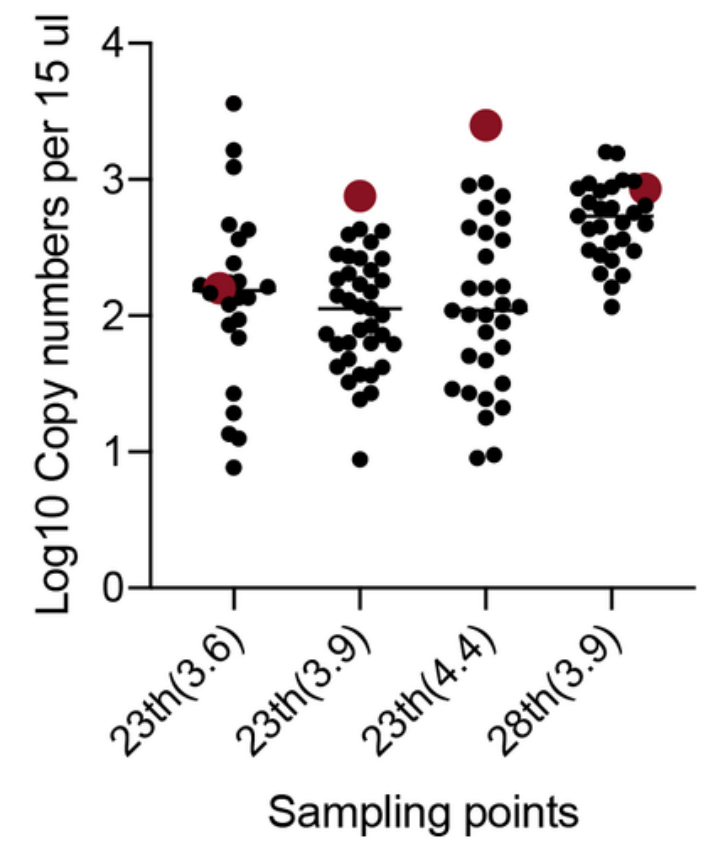

Figure 2 
The viral loads of Patient 14 were consistently higher than other patients. (A) Bar plot showed the viral loads of two confirmed patients' samples at 21th Feb. (B) Dot plot showed the viral loads distribution from the six experimental batches. The dark red points represented the viral load of Patient 14. (C) Dot plot showed the copy number distribution of GAPDH from the five experimental batches containing Patient 14. The dark red points represented the viral load of Patient 14. (D) Dot plot showed the viral loads distribution from the four experimental batches containing Patient 14. The dark red points represented the viral load of Patient 14.

\section{Supplementary Files}

This is a list of supplementary files associated with this preprint. Click to download.

- TableS1.docx 